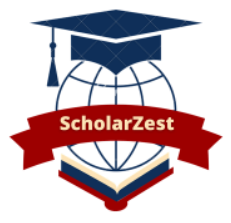

European Scholar Journal (ESJ)

Available Online at: https://www.scholarzest.com

Vol. 2 No. 1, February 2021,

ISSN: 2660-5562

\title{
SILVER NANO DOTS AND THEIR APPLICATION IN BIO BAR CODE ASSAYS AND MEDICINE
}

\begin{tabular}{ll}
\hline \multicolumn{2}{c}{ Article history: } \\
\hline Received: & $2^{\text {nd }}$ January 2021 \\
Accepted: & $13^{\text {th }}$ January 2021 \\
Published: & $3^{\text {rd }}$ February 2021
\end{tabular}

\author{
MS.A.G.J.PATRICIA \\ DEPT. OF PHYSICS, \\ MOTHER TERESA WOMEN'S UNIVERSITY.KODAIKANAL. \\ patriciatrichy@gmail.com
}

\begin{abstract}
:
Nano medicine seeks to deliver a valuable set of research tools and clinically useful devices in the near future. The current medical field is in dire need of new commercial applications in the pharmaceutical industry that may include advanced drug delivery systems, new therapies, and in vivo imaging. Here in this experimental study, the nano materials used in DNA biosensors like silver nano dots were incorporated as nano biosensors are used for both therapeutic and diagnostic applications. The most important step while preparing a DNA biosensor is the immobilization of DNA probe on the surface of a sensing device such as an electrode. The amount of immobilized DNA probe will influence the accuracy sensitivity, selectivity and life of a DNA biosensor directly. Because of the high surface to volume ratio and excellent biological compatibility, nano materials can enlarge the sensing surface area to increase the amount of immobilized DNA and the DNA mixed with nano materials can keep its biologically activity well.In this study, silver nano dots created in our lab were functionalized with thio nucleides and were used as nano sensor probes in bio bar code assays.
\end{abstract}

\section{INTRODUCTION}

Silver nano particles are emerging as a next-generation application in numerous subfields of nano medicine, and potential benefits of using Ag NPs as a prominent nano material in biomedical and industrial sectors have been widely acknowledged. The comprehensive research regarding silver nano materials has been explored nowadays to understand the synthesis methods and mechanisms, characterization of physicochemical properties, and possible toxicity and to discover more promising applications in oncology, personalized healthcare, and pharmacology. $[1],[4],[5],[6],[$ It is known that most of the natural processes take place at nano scale and biological molecules and tissue structurs match sizes of nano dots, So nano dots can be useful for both in vivo and in vitro biomedical research applications.

The integration of nano materials such as nano dots with biological structures can be used for both diagnostic and therapeutic purposes in the field of medicine such drug delivery vehicles, analytical tools, bio sensors, diagnostic devices and physical therapy applications, gene delivery systems, artificial implants treating burn care.Also it was found that silver nano dots can be incorporated into wide range of medical devices such as bone cement, surgical masks, wound dressings and surgical instruments. This technology attempts to attain atto molar sensitivity and combines micro fluidics, silver nano particles encoded with antibodies and DNA to attain extreme high level of sensitivity. It is many times better than the conventional ELISA based assay. It is possible to tag each protein with oligo nucleotide markers that can be subsequently amplified and use DNA detection to identify the target of interest. Often referred to as immune PCR allows one to detect proteins with DNA labels in a variety of different formats. All immune-PCR approaches involve hetero genous assays which involve initial immobilization of a target analyte to $\mathrm{s}$ surface with subsequent detection using an antibody with a DNA label The DNA label is typically strongly bound to the antibody either through covalent interactions or stepavidin -biotin binding.[22],[23].

\section{BIO FUNCTIONALIZATION OF SILVER NANO DOTS TO ACT AS BIO SENSOR PROBES IN BAR CODE ASSAYS. \\ In this study ,Silver nano dots with sizes in the range $<20 \mathrm{~nm}$ were functionalized with thiol oligo nucleides and salted in a 0.5 I Nacl solution, $10 \mathrm{ml}$ phosphate, $0.02 \% \mathrm{SDS}, \mathrm{ph}=7$ over $12-14$ hours. Dna sequence was $5^{\prime}$-HS-AAA AAA AAA AAA AAA AAA AA-4'. Then the silver nano dots were then purified from excess DNA with centrifugations at $23^{\circ} \mathrm{C}$ for $40-50$ minutes. The silver nano dots were washed and finally re suspended in the Nacl, phosphate buffer at concentration of-19.Such silver nano dots were created to act as probes.[22],[23].}


Oligo nucleotide probes for nucleic acid detection are generated using NCBI blast nucleotide search function with DNA sequence.PCR primer design software can be used to generate probe sequences. These sequences are 25-35 base pairs in length .The bar code is 15 mer sequence assigned to each specific protein of interest. Also a universal sequence is included if scano metric assay read out is to be read. This universal sequence is $5^{\prime}$-AGC TAC GAA TAA- $3^{\prime}$. A peg 9 mer is used between the universal sequence and the probe sequence to separate the two.

If using the fluorescence methods an Oligo(da)10 sequence is used to space the recognition element away from the nano dot surface. In either case, the universal sequence or the oligo(da) 10 is the universal sequence or the oligo $(\mathrm{dA}) 10$ is paced between the thiol linkage and the recognition element-barcode sequence. Silver nano dots were used for this purpose as each dot can be tagged to individual bio molecules.[23],[24]

Bar code DNA molecules in the solution must first diffuse to the bottom channel wall and then hybridise with surface bound DNA molecules. It is important to ensure that 1)all released barcode DNA molecules reach the reaction surface,2)there is enough time for the DNA hybridization event to complete.[23],[24],[25],[26]

The diffusion time for DNA molecules in the solution to arrive at the wall is expressed as

$T=h^{2} / D$ where $h$ is the channel height and $D$ is the diffusion coefficient.

Commercially available PSA antibody pair used for indirect ELISA assays was employed in this assay.DNA strands wre synthesized and purified .Thiol modification and synthesis of $10 \mathrm{~nm}$ silver nano dots were carried out using the above mentioned procedure. Functionalized silver nano dots were made by adding polyclonal antibodies of PSA(7mg) to an aqueous solution of $10 \mathrm{~nm}$ silver nano dots i.e $1 \mathrm{ml}$ in $12 \mathrm{~nm}$ solution at $\mathrm{pH} 9.0$ and incubated for d5 minutes. The antibody modified silver nano dots were then reacted with alkyl thiol capped barcode DNA capture strands .4 OD;5,-CAACTTCATCCACGTTCAACGCTAGTGAACACAGTTGTGT-A10-(CH2)3-SH-3, for 15-16 hours. Followed by salt stabilization in $0.1 \mathrm{~m} \mathrm{Nacl}$. The solution was then treated with $.3 \mathrm{ml}$ of a $10 \%$ of BSA solution for 40 minutes to passivate and stabilize the nano dot. The solution was then centrifuged twice foe $1 \mathrm{~h}$ at $4{ }^{\circ} \mathrm{C}$ and the supernatant was removedThe nano dot were redispersed in $0.1 \mathrm{~m} \mathrm{Nacl} / 0.01 \mathrm{~m}$ PBS(pH7.4).Barcode DNAstrand(1od; $5^{\prime}$ CACAACTGTGTTCACTAGCGTTGAACGTGGATGAAGTTG-3') were then allowed to hybridize with the DNA strands coordinated to the nano dot and purified using a similar centrifugation technique.

Bar code detection nano dots were synthesized using $10 \mathrm{~nm}$ silver nano dots functionalized with $3^{\prime}$ alkyl thiol capped oligonulceotides(5'-GCTAGTGAACACAGTTGTGT-A10 $(\mathrm{CH} 2) 3-\mathrm{SH}-3^{\prime}$ through regular procedure. The silver nano dot oligonucleotide recogntion sequence $(20-\mathrm{mer})$ is complementary to half of the target barcode DNA sequence(40mer).[23],[24].

From this study it was found that the nano silver dot based probes acted effectively as bio bar code assays.[20],[21],[24].

\section{RESULTS AND DISCUSSION}

From this study it was analyzed that the silver nano dots of sizes $<20 \mathrm{~nm}$ were efficient as bio probes in bio bar code assays. The results were concurrent with literature survey done during the research period. This new approach yielded very good results at rapid pace and can be applied in DNA technological fields. Nano silver is a safe and effective anti-bactericidal metal because it is nontoxic to animal cells and highly toxic to bacteria such as Escherchia coli(E-Coli) and Staphlococcus aureus and other microorganisms.[21],[22],[23],[24]. Also nano silver in the form of powders as well as suspensions due to high surface to volume ratios has been used as anti-bacterial because it enables the loading of very small quantities of silver and thus makes nano silver medicinal products very cost effective.[20],[21],[22],[23].Thus ,DNA biosensors based on nucleic acid hybridization have been pursued dna biosensors are defined as analytical devices incorporating a single- stranded oligo nucleide probe intimately associated with or integrated within a physical chemical transducer or transducing micro system which may be optical, ,thermometric ,piezoelectric ,magnetic or micro chemical. Because of the high surface to volume ratio and excellent biological compatibility, nano materials can enlarge the sensing surface area to increase the amount of immobilized DNA and the DNA mixed with nano materials can keep its biologically activity well.

\section{CONCLUSION}

It was under stood that bio bar code assays developed using silver nano dots was effective as bio sensors in this field of medicine. The main beneficiary of this study is genetics and tissue engineering where major modifications in gene codes can be done to eradicate in born handicaps and life threatening diseases[22],[23],[24]. It was established from the above study Silver nano dots have the necessary composition as oligonucleotides labels in electro chemical detection assays because silver nano particles exhibit better electrochemical activity. Cai et al reported an electrochemical DNA hybridization detection assay using silver nano particles as the oligo nucleotide labeling tag. The assay relied on the hybridization of the target dna with the silver nano dot-oligo nucleotide DNA probe followed by the release of the ag metal atoms anchored on the hybrids by oxidative metal dissolution.

The nano materials used in DNA biosensors like silver nano dots incorporated nano biosensors are used for both therapeutic and diagnostic applications. The most important step while preparing a DNA biosensor is the immobilization of DNA probe on the surface of a sensing device such as an electrode. The amount of immobilized DNA probe will influence the accuracy sensitivity, selectivity and life of a DNA biosensor directly. 


\section{ACKNOWLEDGEMENTS}

Very thankful to Mr. J.Ramanan .Project Manager. Suntec Micro Systems. Chennai. for his funding this project and continuous support and encouragement throughout this project.

\section{CONFICT OF INTEREST}

The authors express there is no conflict of interest regarding this article.

\section{REFERENCES}

1. A.G.J. Patricia, M.Uma devi Mahalingam .Silver nano dots as Effectve Biosensors in the field of Medicine..IRJET.2017.04(09).284-286.

2. Cunningham AJ. Introduction to bioanalytical sensors. New York: Wiley; 1998.

3. Dahlin $A B$, Tegenfeldt JO, Hook F. Improving the instrumental resolution of sensors based on localized surface plasmon resonance. Anal Chem. 2006;78(13):4416-4423.

4. Dostalek J, Vaisocherova $\mathrm{H}$, Homola J. Multichannel surface plasmon resonance biosensor with wavelength division multiplexing. Sens Actuators B Chem. 2005;108(1-2):758-764.

5. Ilic B, Yang Y, Aubin K, Reichenbach R, Krylov S, Craighead HG. Enumeration of DNA molecules bound to a nanomechanical oscillator. Nano Lett. 2005;5(5):925-929.

6. Joannopoulos JD, Meade RD, Winn JW. Photonic crystals: molding the flow of light. Princeton, New Jersey: Princeton University Press; 1995.

7. Jordan $C E$, Frutos $A G$, Thiel $A J$, Corn RM. Surface plasmon resonance imaging measurements of DNA hybridization adsorption and streptavidin/DNA multilayer formation at chemically modified gold surfaces. Anal Chem. 1997;69(24):4939-4947.

8. Josse F, Bender F, Cernosek RW. Guided shear horizontal surface acoustic wave sensors for chemical and biochemical detection in liquids. Anal Chem. 2001;73(24):5937-5944.

9. Kelly KL, Coronado E, Zhao LL, Schatz GC. The optical properties of metal nanoparticles: the influence of size, shape, and dielectric environment. J Phys Chem B. 2003;107(3):668-677.

10. Kim S, Jung JM, Choi DG, Jung HT, Yang SM. Patterned arrays of Au rings for localized surface plasmon resonance. Langmuir. 2006;22(17):7109-7112.

11. Kim DK, Kerman K, Saito M, Sathuluri RR, Endo T, Yamamura S, Kwon YS, Tamiya E. Label-free DNA biosensor based on localized surface plasmon resonance coupled with interferometry. Anal Chem. 2007;79(5):1855-1864.

12. Hahm J, Lieber CM. Direct ultrasensitive electrical detection of DNA and DNA sequence variations using nanowire nanosensors. Nano Lett. 2004;4(1):51-54.

13. He PG, Dai LM. Aligned carbon nanotube-DNA electrochemical sensors. Chem Commun. 2004;3:348-349.

14. Huang $Y$, Duan $X F$, Wei $Q Q$, Lieber $C M$. Directed assembly of one-dimensional nanostructures into functional networks. Science. 2001;291(5504):630-633.

15. Kim DK, Kerman K, Saito M, Sathuluri RR, Endo T, Yamamura S, Kwon YS, Tamiya E. Label-free DNA biosensor based on localized surface plasmon resonance coupled with interferometry. Anal Chem. 2007;79(5):1855-1864.

16. Kong J, Soh HT, Cassell AM, Quate CF, Dai HJ. Synthesis of individual single-walled carbon nanotubes on patterned silicon wafers. Nature. 1998;395(6705):878-881.

17. Li HX, Rothberg $\sqcup$. Label-free colorimetric detection of specific sequences in genomic DNA amplified by the polymerase chain reaction. J Am Chem Soc. 2004;126(35):10958-10961.

18. Li Z, Chen Y, Li X, Kamins TI, Nauka K, Williams RS. Sequence-specific label-free DNA sensors based on silicon nanowires. Nano Lett. 2004;4(2):245-247.

19. Majumdar A. Bioassays based on molecular nanomechanics. Disease Markers. 2002;18(4):167-174

20. Marazuela MD, Moreno-Bondi MC. Fiber-optic biosensors-an overview. Anal Bioanal Chem. 2002;372(56):664-682.

21. McFarland AD, Van Duyne RP. Single silver nanoparticles as real-time optical sensors with zeptomole sensitivity. Nano Lett. 2003;3(8):1057-1062.

22. Medintz IL, Uyeda HT, Goldman ER, Mattoussi H. Quantum dot bioconjugates for imaging, labelling and sensing. Nat Mater. 2005;4(6):435-446.

23. Patolsky F, Zheng GF, Hayden O, Lakadamyali M, Zhuang XW, Lieber CM. Electrical detection of single viruses. Proc Natl Acad Sci USA. 2004;101(39):14017-14022.

24. Rasooly A, Herold KE. Biosensors for the analysis of food- and waterborne pathogens and their toxins. J AOAC Int. 2006;89(3):873-883. 